Pecvnia, 5 (2007), pp. 29-51

\title{
Algunas consideraciones sobre la ética en el mercado
}

La desconfianza generalizada hacia los dirigentes empresariales refuerza la importancia de la ética en la empresa, tanto en el ámbito meramente teórico-académico cuanto en la aplicación práctica de determinados principios morales a las actividades mercantiles. La responsabilidad social corporativa o empresarial es una concreción de la ética consistente en la asunción voluntaria por parte de las empresas de determinados comportamientos que implican una serie de obligaciones en su ámbito interno y
Montserrat Díaz Méndez

mdmendez@unex.es

Universidad de Extremadura

Fac. de Ciencias Económicas y Empresariales

Dpto. de Dirección de Empresas y Sociología

Avda. de Elvas, s/n

06071 Badajoz (Spain)

Pablo Gutiérrez Rodríguez

pablo.gutierrez@unileon.es

José Luis Vázquez Burguete

jose-luis.vazquez@unileon.es

Universidad de León

Fac. de Ciencias Económicas y Empresariales Dpto. de Dirección y Economía de la Empresa Campus de Vegazana, s/n 24071 León (Spain)
The general distrust towards top management decisions has reinforced/ stressed the importance of business ethics. Social Corporate Responsibility (SCR) is an specific aspect of ethics. It implies the voluntary assumption of certain behaviours and values which may involve several obligations for the company that will affect it as a whole. Nowadays, there exists a discussion about the need of whether establishing or not a law on the content of SCR in order to demand its 
externo. Se discute la necesidad o no de establecer por ley el contenido de la responsabilidad social corporativa y, por tanto, exigir su cumplimiento. Mantener su carácter voluntario no significa que el Estado no pueda establecer unas directrices claras sobre la dimensión social de las empresas, así como su implicación en la sociedad en la que viven y las ventajas para aquellas empresas que lo respeten. Los códigos éticos son un intento normativizador de la ética, que suponen un beneficio para el estado, ya que no se ve obligado a tener que producir normas de derecho positivo y crear sus correspondientes mecanismos de control de conflictos. Por su importancia económica, una especial atención ha merecido la regulación ética de las sociedades cotizadas. En cualquier caso, hay que concienciar de la necesidad de un comportamiento ético basado en la bondad y la justicia, partiendo de que quien actúa éticamente lo hace por convencimiento.

Palabras clave: Ética. Responsabilidad social corporativa. Código ético. Sociedad que cotiza en Bolsa. fulfillment. In this sense, it is important to consider that keeping its voluntary character does not mean that government cannot establish some directives on social commitment.

Ethical codes are an attempt to rule business ethics and imply a direct benefit for government since it avoids the obligation of producing laws and developing control mechanisms. Also, due to the economic importance of stocklisted companies, this paper pays an special attention to their ethical behaviour. As a general conclusion, we remark the idea of concerning society about the need of an ethical business behaviour based on goodness and justice values.

Key words: Ethics. Corporate social responsibility. Code of practice. Companies which are quoted on the stock exchanged.

\section{INTRODUCCIÓN}

Con más frecuencia de la deseada se viene dando a conocer a la opinión pública una serie de escándalos en el mundo empresarial que tienen su origen en comportamientos corruptos de los directivos de las organizaciones públicas y privadas. Tales actitudes no hacen sino constatar una preocupante falta de valores en el enfoque de la gestión de las empresas. Esta situación ha hecho reaccionar a los estudiosos de los diferentes modelos de gestión empresarial, quienes insisten en la importancia que poseen los valores ${ }^{1}$.

El término valor tiene numerosas acepciones. En su sentido filosófico es la cualidad que poseen algunas realidades, consideradas bienes, por lo cual son estimables. Desde este punto de vista nos referimos a valores éticos, lo que podría casi considerarse una redundancia, esto es,

1 Así tanto el modelo de las 7s de Athos y Pascale (strategic, structure, systems, shared values, skills, staff, style), como el del Comportamiento Organizacional, el Enfoque estratégico o, sobre todos, el de la Dirección por Valores. 
principios que rigen el comportamiento de una persona o una organización o grupo. Si bien en última instancia los sujetos activos de actos éticos o no, siempre son las personas físicas.

Una cuestión fundamental que se ha de determinar con carácter previo es qué se entiende por comportamiento ético. Desde una postura tomista, implica una actuación conforme a la naturaleza humana según el querer original de Dios. Para el agnóstico habría que decir, sin embargo, una actuación conforme la naturaleza del hombre, según la concepción naturalista aristotélica y de acuerdo con lo estudiado en las facultades de derecho como derecho natural: es decir un conjunto de normas jurídicas universales e inmutables. No obstante hay quienes ponen en duda la existencia de una serie de virtudes aceptadas por todos como esenciales a la naturaleza humana y niegan la existencia de un derecho natural. Para acudir a unos valores establecidos y aceptados universalmente quizás lo más seguro sea la Declaración Universal de Derechos Humanos ${ }^{2}$, único punto de partida donde podríamos hablar de absoluta y general aceptación.

Lógicamente nadie puede estar en desacuerdo con que determinadas cualidades como honradez, justicia, integridad, son valores deseables en cualquier actuación humana. No obstante el problema surge a la hora de determinar qué conductas concretas integran tales valores y cómo determinarlos. Por ejemplo, un ser íntegro es aquel que actúa de acuerdo con las propias convicciones, pero se puede ser íntegro e injusto si tales convicciones están equivocadas. Se puede apuntar la falacia de nuestro ejemplo argumentando que la integridad implica distinguir reflexivamente entre lo justo o lo injusto, pero ser justo es dar a cada uno lo que le corresponde y su determinación no es fácil. Con todo, lo que se pretende poner de relieve es precisamente la necesidad de determinar de manera más concreta y aplicada a cada actividad y campo de actuación, en qué consiste un comportamiento ético.

La moral, como ciencia que trata del bien y distingue entre las buenas y las malas acciones humanas se utiliza como calificativo del proceder ético. No puede existir una actuación moralmente rechazable y que sea éticamente correcta. El derecho debería ser conforme a la moral 
y a la justicia, pero no siempre es así, hay normas jurídicas que pueden ser consideradas injustas. La moral es más exigente y amplia que el derecho, pues busca una perfección del hombre, de su actuación, que el derecho no puede conseguir ${ }^{3}$. De ahí que, como veremos, no deben rasgarse las vestiduras los juristas porque las normas que regulan el comportamiento moral de las empresas no sean normas de derecho positivo, sino códigos de conducta.

\section{II. ÉTICA Y NEGOCIOS}

La primera cuestión que surge a la hora de analizar este tema es si realmente no se trata de dos términos irreconciliables o contradictorios, imposibles de conjugar ${ }^{4}$. Ciertamente existe una desconfianza generalizada hacia el empresario y los ejecutivos. Probablemente porque se tiene la certeza cuando no la sensación de que muchos de ellos estarían dispuestos a comportamientos poco éticos con tal de conseguir el éxito en los negocios ${ }^{5}$. A ello han contribuido la quiebra de grandes empresas como Enron, Global Crossing, Arthur Andersen o Worldcom, en los Estados Unidos. Las noticias sobre la alta remuneración de los consejeros de grandes empresas, los escándalos inmobiliarios en nuestro país y la recurrente aparición en el cine y las series de televisión del papel del directivo sin escrúpulos, en muchos casos incluso eje central de la trama de ficción, no han ayudado mucho.

Expresiones darwinianas como las de que los negocios son como la jungla, en la que todo vale con tal de conseguir un lucro y solo sobreviven los más capacitados están bastante generalizadas. Incluso se han utilizado de forma sesgada a veces las reflexiones de grandes economistas como el premio nobel Milton Friedman o John Kenneth Galbraith, que no han hecho sino reforzar esa idea de los negocios como

el Siglo XXI. Ensayo 2000

Ver P. Le Tourneau (2000) La Ética de los Negocios y de la Administración en

4 Ver al respecto a A. Durán-Pich (2005) "¿Es la ética en los negocios un oxímoron?. Una aproximación contextual a un tema controvertido", XIV Seminario Permanente de Ética Económica y Empresarial (2004-2005). Ética de la Empresa: "Hacia un Nuevo Orden Global", Valencia, Fundación Étnor, pp. 31-45. Donde el autor, utilizando el término oxímoron inventado por Jorge Luis Borges para hacer referencia a conceptos contradictorios, reflexiona sobre este tema.

5 En las encuestas que el Wall Street Journal periódicamente lleva a cabo para los ejecutivos, la mayoría de ellos reconoce que a pesar de que la ética les supone un impedimento, estarían dispuestos a pasarla por alto con el fin de obtener éxito. 
actividades per se sospechosas. Ciertamente, Milton Friedman ha defendido que la única responsabilidad social de una empresa es hacia sus accionistas, lo que supone una clara posición contraria a la responsabilidad social corporativa sobre la que luego hablaremos ${ }^{6}$. Sin embargo, en ningún caso sus palabras pueden interpretarse como que a su juicio la actividad empresarial deba estar exenta de valores. Galbraith, por su parte, ha sido uno de los más famosos críticos de una actividad tan ligada al mundo de los negocios como es la publicidad. Para él su función principal no es facilitar al consumidor información sobre los productos o servicios que se encuentran en el mercado, para que pueda elegir el que más satisface sus necesidades o se adapta a sus posibilidades, sino que simplemente tiene como finalidad crear deseos antes inexistentes. Es decir, para Galbraith, la publicidad es intrínsecamente una actividad poco ética ${ }^{7}$. Responden estas visiones, hoy en gran parte superadas, a una concepción de la "empresa autista" como una organización volcada hacia la contabilidad y los clientes, aséptica frente a consideraciones morales, que deben predicarse de la esfera privada de los individuos, como algo disociado de los negocios ${ }^{8}$.

Desde hace algunos años, sin embargo, prevalece una visión de los negocios desde un punto de vista mucho más social. La empresa, su simple existencia, ya es algo beneficioso para la sociedad. No sólo porque su finalidad es satisfacer las necesidades del mercado, aunque satisfaciendo las suyas propias lucrativas, sino porque genera empleo y paga impuestos, en definitiva, es la más importante fuente generadora de la riqueza de un país. Ya no es esa organización cerrada y únicamente enfocada a los clientes y al balance ${ }^{9}$, sino una actividad estrechamente unida al bienestar de cada ciudadano. Ha desaparecido o se ha atemperado sensiblemente el mito de la empresa como ente sin alma o el de la maldad congénita de los negocios.

En el contexto descrito nace la ética de la empresa como una de las denominadas éticas aplicadas, como consecuencia de la preocupación

\footnotetext{
M. Friedman (1982) Capitalism and Freedom. Chicago: University of Chicago Press. J.K. Galbraith (1958) The Affluent Society. New York: Mariner Books. cuenta el triple balance (económico, social y medioambiental).
} 
en remoralizar la sociedad ${ }^{10}$. Hoy en día afortunadamente hablar de ética de la empresa sigue de moda. Los filósofos, los empresarios, los accionistas, las organizaciones internacionales, los gobiernos de los estados, los economistas, todo el mundo se interesa por la aplicación de determinados principios éticos en el mercado. Y seguirá siendo un tema estudiado en el futuro, como lo asegura el hecho de que en todas las universidades que han elaborado o van a elaborar sus nuevos planes de estudios del área de la economía o afines, tanto en el grado como en el postgrado, hayan introducido o vayan a introducir, en la mayoría de los casos además con carácter obligatorio, una asignatura sobre ética empresarial.

La ética de los negocios surge en cierto sentido como una revolución, puesto que es la respuesta a una demanda social, de los ciudadanos, no de los dirigentes. Sin embargo, en la empresa, al igual que en cualquier otra organización, la única forma posible de que los valores sean compartidos y se institucionalicen, es cuando existen líderes que determinen los valores y comportamiento de toda la organización. De ahí que resulte fundamental el compromiso de los ejecutivos para que la empresa y los negocios tengan en cuenta los valores éticos, para que éstos constituyan el carácter de la empresa. De esta forma, será factible que todos los miembros de la organización puedan actuar éticamente, sin necesidad de tener que asumir el papel de héroes ${ }^{11}$.

Afortunadamente, hoy en día, como decíamos anteriormente, la ética interesa no sólo a los filósofos, sino también a los economistas, a los juristas y a los consumidores, lo que implica la aceptación de la idea de que si bien la finalidad de los negocios es el lucro, no es incompatible con una regulación de la actividad en el mercado que evite comportamientos no éticos. Y esto es así porque la ética es rentable para las empresas. No nos referimos a que invertir en negocios éticos produzca más beneficios. De hecho, han existido y existen fondos de inversión que, por razones éticas, excluían de sus inversiones a negocios o empresas determinadas, y

10 A. Cortina Orts (2005) "Hacia una nueva cultura empresarial (1994-2005)", en XV Seminario Permanente de Ética Económica y Empresarial (2004-2005). Ética de la Empresa: "Hacia un Nuevo Orden Global", Valencia, Fundación Étnor, pp. 7-19, en páginas 13 a 15, explica las cinco razones del afán por la incorporación de la ética a las distintas ramas. Tales razones son el fin de las ideologías; la necesidad de que exista confianza para el buen funcionamiento de la economía; las buenas prácticas empresariales; la idea de que la ética es rentable; la existencia de una ética cívica, compartida por todos los ciudadanos. 
no demostraron que su rentabilidad fuera superior al resto de fondos ${ }^{12}$. Desde luego, tiene lógica pensar que cuando una empresa lleva una política empresarial ética su gestión será buena $y$, consiguientemente, las probabilidades de que el valor de sus acciones caiga de forma significativa, por pérdida de reputación, o toma de decisiones empresariales equivocadas, son mucho menores. Por ello existen analistas que recomiendan a sus inversores sólo empresas social y éticamente responsables ${ }^{13}$. En la actualidad la rentabilidad de la empresa ética radica en la confianza que genera ${ }^{14}$. Tanto en el ámbito interno de la empresa, es decir, sus trabajadores son más conscientes de estar realizando una labor positiva para la comunidad, contribuyendo a su progreso y bienestar; como para los consumidores, o si se prefiere, desde un punto de vista más puramente mercantilista, para los clientes, cuyo numero potencial aumenta de esta forma. De ahí que muchas empresas destinen parte de sus beneficios, siquiera de forma testimonial, a patrocinar o subvencionar ONGS o actividades benéficas, asistenciales o de tipo cultural, no lucrativas y a dar a conocer al público en general que realizan actuaciones de ese tipo. Ciertamente, no es este modelo de comportamiento ético efectista e interesado el ideal, pero si merece la pena citarlo para demostrar los beneficios que en todo caso conlleva una mayor o menor asunción de comportamientos éticos en el mercado. En cualquier caso, y aunque se hagan esfuerzos en encontrarle rentabilidad al comportamiento ético empresarial, en el fondo la mejor defensa de la ética en los negocios, la que se establece sobre bases más sólidas, es sin duda el convencimiento personal de que los seres humanos deben tener un comportamiento ético, independientemente de cual sea el resultado o consecuencias económicas del mismo. Como decía Santo Tomás, el premio de la virtud es el honor ${ }^{15}$, por más que la defensa de los beneficios empresariales de la ética sea extremadamente útil para convencer a quienes no comparten esta idea.

12 El Pax World Fund, de los Estados Unidos, excluía de sus inversiones empresas y negocios relacionados con la guerra del Vietnam. El Stewarship Fund británico, no invertía en empresas que negociaran con Sudáfrica, como protesta por el apartheid.

13 Es el concepto de inversión socialmente responsable, como el caso del Social Investment Forum, creado en 1991 en el Reino Unido, y otros tipos de fondos que existen en Francia, Alemania o Holanda, por ejemplo.

14 Ver A. Cortina Orts (Coord.) (2003) Construir confianza: ética de la empresa en la sociedad de la información y las comunicaciones. Madrid: Trotta. Ver también D. García Marzá (2004) Ética empresarial: del diálogo a la confianza. Madrid: Trotta.

15 Locke, de igual forma, sostenía que el premio de la virtud es ella misma. 
La ética de los negocios debe ser una ética de las personas, porque, como decíamos, al fin y al cabo, los comportamientos éticos dependen de las personas. Pero tales comportamientos deben transmitirse e imbuir a las organizaciones. Debe, por otra parte, estar enfocada hacia resultados palpables, pues de lo contrario estaríamos ante un conjunto de grandes y buenas ideas, pero etéreas y sin funcionalidad alguna. No obstante, no debe centrarse únicamente en el resultado, sino que para que sea una actuación permanente, una manera de entender las actividades que los diferentes agentes económicos realizan en el mercado, debe estar basada en el convencimiento. $\mathrm{Y}$, por último, tiene que tener en cuenta a todos los afectados por la actividad económica, cuestión que trataremos en el siguiente apartado.

\section{LA RESPONSABILIDAD SOCIAL CORPORATIVA}

\section{Concepto}

Para la Unión Europea, la responsabilidad social corporativa o responsabilidad social empresarial es un "concepto con arreglo al cual las empresas deciden voluntariamente contribuir al logro de una sociedad mejor y un medio ambiente más limpio", o, de manera más completa, "la integración voluntaria, por parte de las empresas, de las preocupaciones sociales y medioambientales en sus operaciones comerciales y sus relaciones con sus interlocutores" ${ }^{16}$.

La responsabilidad social corporativa es una dimensión de la ética del mercado. Su principal misión es mejorar la ética en el mercado mediante la asunción interna por parte de las empresas de determinados comportamientos éticos. En este sentido se trata de un forma concreta de entender la ética empresarial.

La idea central del concepto de responsabilidad social corporativa es que las empresas no tienen únicamente obligaciones para con sus accionistas (stockholders), sino también para con sus trabajadores, proveedores, consumidores y comunidad en general (stakeholders). El objetivo de una empresa no es obtener beneficio, sino servir a los

16 Libro Verde elaborado por la Comisión: "Fomentar un Marco Europeo para la Responsabilidad social de las empresas", Bruselas, 18 de Julio de 2001, COM (2001), 366 final, parágrafos 8 y 20. 
ciudadanos, satisfaciendo sus necesidades. El medio para cumplir con esta misión, no el fin, es la actividad económica lucrativa.

Se distinguen dos dimensiones en la responsabilidad social corporativa o empresarial: interna y externa. Interna, es decir, enfocada básicamente a la gestión de los recursos humanos. Así, una empresa será socialmente responsable cuando promueva la formación de sus trabajadores; arbitre medidas que les permitan compaginar el tiempo dedicado al trabajo con el dedicado a la familia y a su ocio; no discrimine a sus empleados y les trate de forma igual, con independencia de su sexo e ideología, a la hora de la retribución y promoción profesional; permita a los trabajadores que participen en los beneficios; se preocupe de la seguridad y salud de sus empleados; lleve a cabo prácticas responsables de contratación de minorías étnicas, discapacitados y en general de colectivos desfavorecidos. La dimensión externa, por su parte, implica una colaboración con la comunidad donde radica la empresa, con los proveedores; producir productos seguros y ecológicos para los consumidores, respetar los derechos humanos y las condiciones dignas de trabajo, en este último caso, cuando se trata de empresas establecidas en países en vías de desarrollo.

\section{La RSC generadora de confianza}

Es la propia sociedad quien otorga legitimidad a la empresa. Si la empresa no responde a las expectativas que ha generado la consecuencia será una inevitable pérdida de crédito ${ }^{17}$. Una empresa sólo puede generar confianza si a la hora de tomar sus decisiones tiene en cuenta los intereses de todos los afectados, y no sólo de los accionistas. En primer lugar, lógicamente, deberá proporcionar a los consumidores productos y servicios de calidad. Pero también es cada vez más numeroso el grupo de consumidores que introducen en la toma de sus decisiones de consumo valoraciones sobre aspectos éticos, medioambientales o ecológicos de la empresa. Esto supone, sin duda, un impulso a la responsabilidad corporativa de las empresas, algo ya asumido por la inmensa mayoría de grandes empresas. No obstante, la dificultad será hacer que la actuación socialmente responsable de la empresa no se quede en una mera declaración

17 K. Davis (1990) "Five Propositions for Social Responsibility", en W.M. Hoffman, J. Mills, J. Moore: Business Ethics: Readings and Cases in Corporate Morality. New York: McGraw-Hill. 
de intenciones, que no sea un simple recurso estratégico, sino que, por el contrario, sea consecuencia de la implantación de una cultura ética empresarial convencida. De hecho, los conocidos modelos de gestión de la calidad total (TQM) y de excelencia empresarial (EFQM) cambian el concepto estricto tradicional de cliente por uno más amplio que distingue entre cliente interno (personas de la organización a quien se pasa el trabajo) y externo (usuario o consumidor), e incluso entiende que el indicador de la excelencia no es únicamente la satisfacción del cliente, sino también del personal y la sociedad. Pero, en cualquier caso, siempre como una estrategia competitiva, alejada de cualquier consideración ética.

La credibilidad de la responsabilidad social corporativa requiere que se pase de las declaraciones de intenciones a la acción. De lo contrario, el excesivo tratamiento teórico de un tema indudablemente de moda y al mismo tiempo tan evidentemente bondadoso sólo pude perjudicar su imagen y la de las empresas que la proclaman. La palabra clave es compromiso. Compromiso de las empresas que necesitará no sólo lo que ya hemos indicado que se está produciendo, esto es, la aceptación pública de los principios que regulan la responsabilidad social empresarial sino, sobre todo, la determinación de los mecanismos establecidos para que todos los implicados puedan, en mayor o menor medida, participar en la toma de decisiones. Y además, como colofón, se deberán hacer públicos los objetivos concretos asumidos por las empresas, fundamentalmente a través de las memorias ${ }^{18}$, y su sometimiento periódico a una auditoría al respecto ${ }^{19}$.

18 Es de destacar la guía GRI (Global Reporting Initiative), creada en 1997 por la la ong CERES (Coalition for Environmentally Responsible Economies) junto con PNUMA (Programa de las Naciones Unidas para el Medio Ambiente) y actualizada en el año 2002, cuyo objetivo es fomentar la calidad, rigor y utilidad de las denominadas memorias de sostenibilidad, donde las empresas informan de su actividad en tres niveles: económico, medioambiental y social.

19 Hasta la fecha existen una serie de sistemas de gestión empresarial normalizados que recogen aspectos parciales de la responsabilidad social corporativa. Por ejemplo la Social Accountability 8000 (SA 8000) de la Social Accountability International, basada en las recomendaciones de la OIT, la Declaración Universal de los Derechos Humanos y la Convención de Derechos del Niño de la ONU, básicamente. O la ISO 14001, sobre gestión medioambiental. También merece la pena reseñar la SD 2100, de la Asociación Francesa de Normalización. En la actualidad se está en proceso de elaboración de una norma que si recogerá de forma más completa lo que es la responsabilidad social corporativa, y que verá la luz en el 2009: la ISO 26000. 


\section{La voluntariedad de la RSC}

La voluntariedad es una característica que aparece de forma constante en todas las definiciones y conceptos de responsabilidad social corporativa o empresarial. Este carácter voluntario en cuanto comportamiento ético, como ciudadano ejemplar no puede llevarnos a creer que cada empresa debe llevar a cabo una serie de actividades filantrópicas, a través de fundaciones creadas ad hoc o departamentos propios. Por el contrario, como ya hemos reiterado, el concepto de responsabilidad social debe formar parte de la cultura empresarial, siendo esta una idea fundamental para diferenciar el concepto que nos ocupa y el de filantropía. Abundando en el tema, Conill y Garcia-Marzá señalan acertadamente que la diferencia entre responsabilidad social y filantropía estriba en que mientras ésta es una ética de máximos, es decir, implica el altruismo, la generosidad en todos deseables, pero en ningún caso exigibles, la responsabilidad social es una ética de mínimos, en cuanto sí es exigible que la empresa tenga capacidad para responder a las demandas de la sociedad ${ }^{20}$.

Siendo unánimes las posturas sobre la exigibilidad de la responsabilidad social corporativa, existen grandes discrepancias en el grado de exigencia y en el modo de articularla. Básicamente, el debate se centra en si debe articularse una norma jurídica que establezca las obligaciones de las empresas en este ámbito o, por el contrario, si, como sucede en la mayoría de los países, lo más adecuado es la autorregulación. Es decir, se discute si el término voluntariedad debe o no debe ir unido al concepto de responsabilidad social.

Los que defienden la no necesidad de una regulación legal de la responsabilidad social corporativa parten de la idea de que cualquier empresa, por el simple hecho de realizar su actividad con respeto a las normas, generar empleo, pagar impuestos, en definitiva, crear riqueza para el país, ya está cumpliendo una importante labor social $y$, consecuentemente se les puede calificar de socialmente responsables. Quienes opinan así confunden las evidentes finalidades sociales de las empresas por el simple hecho de su existencia y actuación en el más

20 J. Conill y D. García-Marzá (2004) "Responsabilidad social corporativa: ¿ética, derecho o filantropía?", XV Seminario Permanente de Ética Económica y Empresarial (2004-2005). Ética de la Empresa: "Hacia un Nuevo Orden Global", Valencia, Fundación Étnor, pp. 118-125, en p. 120. 
absoluto respeto a la ley, con la dimensión ética que debería siempre existir en ellas. Ese plus de voluntario compromiso ciudadano y social que excede las obligaciones estrictamente legales que todo empresario tiene que cumplir es la responsabilidad social corporativa o empresarial.

La supervivencia de la empresa requiere ineludiblemente la existencia de rentabilidad. Es irreal e ingenuo creer que la finalidad de las empresas, el motivo de su creación no es el ánimo de lucro. Sería por otra parte ir contracorriente cuando por ejemplo incluso las empresas de base mutualística, como la cooperativa, son a todas luces sociedades mercantiles, aunque en algún tiempo pasado se pusiera en duda esta idea, hoy ya superada. La constitución de una empresa mercantil siempre conlleva una actividad lucrativa para los socios. Quien desea realizar una actividad puramente benéfica, social, cultural, religiosa, etcétera, acude a otras formas organizativas, como fundaciones o asociaciones.

Establecer por ley el contenido de la responsabilidad social corporativa y, por tanto, exigir su cumplimiento, amén de desnaturalizar su concepto, pues ya no se podría en puridad hablar de responsabilidad, sino de cumplimiento legal, sólo conllevaría, a nuestro juicio, inconvenientes. En un momento en que se pretende agilizar y favorecer tanto la constitución como el funcionamiento de las empresas, a fin de incentivar su creación, el añadir las exigencias sociales sobre las que estamos hablando sólo podría traer como consecuencia un encarecimiento de los costes de funcionamiento empresarial que se traducirían en un incremento de precios, así como supondría un elemento desincentivador de la iniciativa empresarial. Esto no significa que no aboguemos por el establecimiento desde la administración pública, con la implicación de los empresarios, de unas directrices claras sobre la dimensión social de las empresas y su implicación en la sociedad en la que viven. 0 que estemos en contra de que se puedan acordar alunas ventajas para aquellas empresas que siguen las directrices establecidas sobre una política empresarial realmente con una preocupación social responsable ${ }^{21}$.

21 Por ejemplo una mayor puntuación de acuerdo con el baremo publicado a efectos de concurrir a concursos o licitaciones públicas. 


\section{Principales iniciativas sobre RSC}

Aunque hay multitud de iniciativas nacionales e incluso internacionales de organizaciones no gubernamentales y organismos internacionales y supranacionales en esta materia, centrándonos en aquellas que tiene una mayor importancia e influencia, destacan sin duda tres: el ya citado Libro Verde de la Unión Europea, El Pacto Mundial y las Líneas Directrices de la OCDE para Empresas Multinacionales.

En su discurso ante el Foro Económico Mundial, el 31 de enero de 1999, el entonces secretario general de la ONU, Kofi Annan, propuso por vez primera que los dirigentes empresariales colaboraran de forma voluntaria con los propios organismos de la ONU, la sociedad civil y las organizaciones laborales a promover principios sociales y ambientales de carácter universal. Esta iniciativa, denominada Pacto Mundial, persigue fomentar la responsabilidad cívica de las empresas en la economía mundial. Se trata de un instrumento no normativo, en cuanto no impone las medidas que se deben tomar, ni evalúa o audita las acciones que las empresas lleven a cabo al respecto. Para su desarrollo se creó la Oficina del Pacto Mundial, con la que colaboran directamente seis organismos de la ONU: la Oficina del Alto Comisionado para los Derechos Humanos; el Programa de las Naciones Unidas para el Medio Ambiente; la Organización Internacional del Trabajo; el Programa de las Naciones Unidas para el Desarrollo; la Organización de las Naciones Unidas para el Desarrollo Industrial y la Oficina de las Naciones Unidas contra la Droga y el Delito. El Pacto Mundial se basa en diez principios de consenso universal que se pide a las empresas que hagan suyos. Estos principios se refieren a cuatro ámbitos: los derechos humanos, las relaciones laborales, el medio ambiente y la lucha contra la corrupción ${ }^{22}$.

Las Líneas Directrices de la OCDE para Empresas Multinacionales son una serie de recomendaciones, redactadas en el año 2000 y dirigidas fundamentalmente a las empresas multinacionales ${ }^{23}$, puesto

22 Los principios han sido extraídos de la Declaración Universal de Derechos Humanos; la Declaración de Principios de la Organización Internacional del Trabajo relativos a los derechos fundamentales en el trabajo; la Declaración de Río sobre el Medio Ambiente; la Convención de las Naciones Unidas sobre la Corrupción. Sobre estos principios, quienes son las empresas participantes y como se estructura el Pacto Mundial, visitar la página Web www.unglobalcompact.org, o, en España, la página de la Asociación Española del Pacto Mundial (ASEPAM), www.pactomundial.org, donde se pude ver que hay 518 empresas españolas adheridas.

23 Entendiendo por empresa multinacional tanto la sociedad o empresa madre o holding, como cualquier filial o sociedad local. 
que disponen de más medios que las pymes, aunque el objetivo es que tanto unas como otras ejerzan sus actividades de acuerdo a las mismas reglas de conducta. Los principios generales de las directrices se basan en que las empresa deben contribuir al progreso económico, social y medioambiental, con el fin de lograr un desarrollo sostenible; respetar los derechos humanos; estimular las capacidades locales; crear empleo y formación; apoyar y defender el uso de buenas prácticas de gobiernos empresarial; no adoptar medidas disciplinarias o discriminatorias contra los trabajadores que elaboren de buena fe informes para la dirección de la empresa o autoridad pública competente, sobre prácticas contrarias a la ley o a las propias directrices; alentar a que sus socios, proveedores y subcontratistas apliquen conductas compatibles con las directrices; abstenerse de cualquier ingerencia indebida en actividades políticas locales.

Más en concreto las Directrices de la OCDE recomiendan actuaciones en ocho campos. En lo referente a la publicidad de sus operaciones, ya que las empresas deben dar una información periódica, fiable y relevante de sus actividades, estructura, situación financiera y resultados. En el ámbito del empleo y relaciones laborales, en cuanto tienen que respetar el derecho a la representación de los trabajadores, luchar contra la abolición del trabajo infantil y el forzado, no discriminar por motivos de sexo, raza o religión, y velar por la seguridad y salud de los trabajadores. Por lo que respecta al medio ambiente, ya que debe establecer un sistema de gestión medioambiental eficaz. En la lucha contra la corrupción, no ofreciendo, ni prometiendo, ni dando, directa o indirectamente pagos ilícitos o ventajas indebidas para obtener o conservar un contrato o una ventaja. También en lo relativo a la defensa de los intereses de los consumidores y usuarios, al no realizar prácticas comerciales de marketing y publicitarias injustas, debiendo garantizar la seguridad y calidad de los bienes y servicios que ofrecen. En el campo de la ciencia y la tecnología, las empresas deben contribuir al desarrollo de la capacidad innovadora local y nacional. Deben por supuesto abstenerse de realizar actos contrarios a la libre competencia. Y, por último, en el tema de la fiscalidad, deberán pagar puntualmente sus deudas fiscales.

Para favorecer la eficacia de las directrices se crean los Puntos Nacionales de Contacto, funcionarios u organismos de la administración de cada uno de los países que han suscrito las directrices, cuya misión es defenderlas, responder a las consultas que se le realicen y contribuir a la resolución de problemas que surjan en relación con su aplicación. Cada Punto Nacional elabora un informe anual dirigido al Comité 
sobre Inversión Internacional y Empresas Multinacionales de la OCDE, quien estudia estos informes, las peticiones de los suscriptores, realiza aclaraciones a las directrices y formula recomendaciones para su idónea aplicación.

\section{UN INTENTO DE NORMATIVACIÓN: LOS CÓDIGOS ÉTICOS}

\section{1. Ética y Derecho}

La ética empresarial no puede equipararse a la ley, puesto que si bien ésta es imprescindible para la convivencia, lo cierto es que desde la óptica de la ética, la ley muchas veces es a todas luces insuficiente para garantizar una conducta ética. De hecho, no es extraño asistir a conductas legalmente intachables, pero éticamente reprobables. Esto no significa que el Derecho sea amoral ${ }^{24}$. En su conjunto el Derecho debe ser considerado como un instrumento de coordinación ética entre los miembros de una comunidad, asegurando unos mínimos de justicia ${ }^{25}$. Pero lo que es evidente es que resulta en muchos casos insuficiente en términos estrictamente éticos. Es decir, no se puede afirmar que el Derecho garantice ese mínimo ético al que anteriormente nos hemos referido. Aunque sin olvidar que existen determinadas normas jurídicas que tienen su fundamento declarado en razones estrictamente éticas o morales. Por ejemplo, el artículo 1255 del Código Civil, al establecer la libertad de pactos en los contratos, siempre que no sean contrarios a las leyes, orden público o moral; o el artículo 1275, del mismo cuerpo legal, cuando establece que será causa ilícita en los contratos aquella que se oponga a las leyes o a la moral, o la referencia a la buena fe del artículo 1259 del reiterado Código, o a la diligencia del buen padre de familia de los artículos 1094, 1104 y 1889, todos ellos también del Código Civil. En definitiva, conceptos amplios que flexibilizan y corrigen el derecho estricto. Aunque el caso más paradigmático para los juristas sería sin duda la Ley de Represión de la Usura de 23 de Julio de 1908, a la que se ha calificado

24 Ver K. Larenz (1993) Derecho justo: fundamentos de ética jurídica. Madrid: Civitas.

25 Ver G. Orozco Pardo (2002) "Protección de los consumidores, condiciones generales y cláusulas abusivas. Varias reflexiones y un ejemplo: el sistema francés de amortización de créditos hipotecarios", Aranzadi Civil, núm. 10, pp. 15-58. 
como norma de carácter jurídico y finalidad eminentemente ética ${ }^{26}$. Nuestro tribunales de justicia, si bien no frecuentemente, también fundamentan sus fallos, amén de en el derecho positivo, como no podía ser de otra manera, en la ética ${ }^{27}$.

\section{Ventajas e inconvenientes de los Códigos éticos}

La proliferación de normas de conducta, ya sea bajo la denominación de códigos deontológicos, códigos éticos o simplemente códigos es, como señala Fernández de la Gándara, la expresión normativa de la moderna moral negocial ${ }^{28}$. La teoría reductivista de que el estado es la única fuente generadora de normas jurídicas hace años que ha sido superada. El ejemplo más claro es el poder autonormativo que poseen las asociaciones, siempre que no excedan los límites de su competencia, tanto objetiva cuanto subjetiva. Tanto desde el punto de vista de su objeto social, el fin para el que se han constituido; como el ámbito de aplicación reducido a los miembros de la asociación. Y, por supuesto, siempre que no contradigan las leyes estatales.

La existencia de estos códigos supone un beneficio para el Estado, ya que no se ve obligado a tener que producir normas de derecho positivo y crear sus correspondientes mecanismos de control de conflictos al respecto. En la parte negativa, sin embargo, está algunas veces su poca efectividad, puesto que carecen normalmente del carácter coercitivo y sancionador de las leyes. También ha sido criticado el procedimiento de creación de los códigos, no sometido a ningún control, no ya parlamentario, sino ni tan siquiera de grupos de opinión o simplemente el de los medios de comunicación social. Estos inconvenientes pueden generar el escepticismo de algunos.

26 A. Iñigo Fuster (2003) "Nulidad y usura. La nulidad del préstamo usurario a la luz de la Ley de Represión de la Usura", Sentencias de Tribunal Supremo, Audiencias Provinciales y otros tribunales, núm. 16, Pamplona: Aranzadi.

27 La Sentencia de Nuestro Tribunal Supremo ya rechazaba los contratos leoninos por ser contrarios a las más elementales reglas de la ética. Normalmente los fundamentos éticos en nuestra jurisprudencia suelen ir unidos a las sentencias del Tribunal Constitucional ligadas al ejercicio de derechos fundamentales (intimidad personal y familiar, libertad de expresión, honor, libertad religiosa y de culto, etc.).

28 L. Fernández de la Gándara (1993) "Derecho. Ética y Negocios", Discurso de Apertura del curso 1993/94 en la Universidad de Alicante, Alicante, pág. 8. 
En defensa de este sistema de autorregulación, hay que reconocer que constituyen la mejor alternativa a la incapacidad o desidia de los ordenamientos jurídicos estatales para ofrecer soluciones a determinados problemas de la cambiante realidad económica. Además, cuando el propio sistema establece un adecuado mecanismo de control de la observancia de las normas del código, en parte se palian las objeciones a la falta de mecanismos de responsabilidad a la que antes aludíamos. Si el código es aceptado por una gran mayoría de los agentes del mercado en el sector al que pretende regular, será sin lugar a dudas un medio adecuado para crear la conciencia general de la observancia de sus reglas. Por último, en este apartado de pros y contras, no debemos olvidar que la existencia del código y sus mecanismos de control de su cumplimiento no impide en ningún caso el derecho de cualquier ciudadano, persona física o jurídica, a acudir a los tribunales de justicia. Con esto queremos decir que los códigos, sirven, por un lado, para descongestionar la saturada administración de justicia $y$, por otro, cuando previamente se ha acudido al sistema autorregulador para dirimir un conflicto antes de la vía judicial. La decisión del órgano competente del sistema de autorregulación en la interpretación del código siempre suele ser un antecedente a tomar en consideración, por su alto grado de especialización, por los propios tribunales de justicia, a la hora de su enjuiciamiento.

Un claro ejemplo de lo antedicho lo tenemos en los diferentes códigos que aplica la Asociación para la Autorregulación de la Comunicación Comercial $^{29}$. En una materia tan controvertida como la publicidad, el Jurado de la Publicidad de Autocontrol realiza una importante y efectiva tarea. Prueba evidente es el número de resoluciones, que en el año 2006 ascendió a 117 , siendo 16 la media de días que necesita el Jurado para dictarlas ${ }^{30}$. Sin contar con el servicio de control previo de la licitud de los mensajes publicitarios, que ofrece también la Asociación. Es el denominado copy advice, un examen previo del mensaje que va a ser publicitado, cada vez

29 Dos códigos éticos: Código de Conducta Publicitaria y Código Ético de Comercio Electrónico y Publicidad Interactiva, y 11 códigos sectoriales (fabricantes de productos de nutrición, tecnología sanitaria, bebidas espirituosas, medicamentos, software, alimentos, cerveza, juguetes, etc.).

30 Si lo comparamos con el tiempo en que se obtiene una resolución judicial, las diferencias son abismales. Además, otro datos significativo es que en los diez años de existencia del Jurado, de los 1.675 casos resueltos, tan sólo 25 fueron reclamados posteriormente ante los Tribunales de Justicia (fuente: memoria de Autocontrol de 2006, en www.autocontrol.es). 
más utilizado en cuanto no garantiza, pero evita en la mayoría de los casos, futuros litigios ${ }^{31}$.

3. La especial regulación de la ética en las sociedades que cotizan en Bolsa

La separación entre los propietarios de las empresas y sus gestores produce en muchos casos numerosos conflictos de intereses que pueden afectar negativamente a la imagen y valor de la empresa y perjudicar los intereses de sus accionistas. Cuando se trata de sociedades que cotizan en Bolsa, la trascendencia de este problema es aún mayor, por lo que los gobiernos y autoridades encargadas de la supervisión del mercado de valores se han mostrado especialmente interesadas en establecer mecanismos que garanticen un comportamiento responsable de los administradores de tales sociedades que incremente la transparencia de ese mercado.

Se trata de una tendencia iniciada a principios de los años noventa en la inmensa mayoría de los países desarrollados, así como en organizaciones internacionales como la OCDE o la Unión Europea ${ }^{32}$. Se han elaborado los generalmente denominados códigos de buen gobierno que desarrollan principios reguladores de aspectos tan importantes como los derechos de los accionistas, el tratamiento equitativo, la función de los grupos de interés, la comunicación y transparencia deseable por parte de las sociedades y la responsabilidad del consejo de administración.

En España se creó una Comisión Especial para el estudio de un código ético de los Consejos de Administración de las Sociedades, presidido

31 El número de solicitudes de copy advice en el 2006 fue de casi 3.700 , lo que supone un incremento del 27\% respecto al año 2005 (fuente: memoria de Autocontrol de 2006, en www. autocontrol.es).

32 El Código referencia es el denominado Informe Cadbury (1992) del Reino Unido, hoy sustituido por el Código Combinado, creado por el Comité Hampel en 1998. Pero hay otros muchos Códigos similares: Informe Ali, en USA (1992); Informe Dey, en Canadá (1993); Informe King, en Sudáfrica (1994); Informe Viento, en Francia (1995, actualizado en 1999); Informe Cardon, en Bélgica (1998); Informe laim, en Irlanda (1991); Informe Peters, en Holanda (1997); principios en materia de gobierno corporativo de la OCDE (1998). En la Unión Europea hay que destacar una serie de normas al respecto, como las Recomendación de 15 de Febrero de 2005 (2005/162/EC) sobre consejeros externos y comisiones del Consejo; y la de 14 de Diciembre de 2004 (2004/913/EC) sobre retribuciones de consejeros de sociedades cotizadas. También son importantes las Recomendaciones de sobre buen gobierno de las entidades de crédito, del Comité de Supervisores Bancarios de Basilea (Enero del 2006). 
por D. Manuel Olivencia Ruiz ${ }^{33}$. Fruto de esta Comisión fue el denominado Informe Olivencia, publicado en 1998, base de los posteriores trabajos a los que nos referiremos. El Informe Olivencia recoge 23 recomendaciones dirigidas a los consejos de administración, tales como las de incorporar consejeros externos, no vinculados a la dirección de la empresa; separara los cargos de presidente y primer ejecutivo; crear comisiones delegadas o sobre la frecuencia de las reuniones del consejo y la reducción del número de consejeros, para agilizar la toma de decisiones. Todas ellas con el objetivo de "modernizar los consejos, haciéndolos más operativos y transparentes, de forma que sirvan eficazmente el interés social". La labor de la Comisión Olivencia fue continuada por la Comisión Especial para el Fomento de la Transparencia y Seguridad de los Mercados Financieros y Sociedades Cotizadas (Comisión Aldama), creada en septiembre de 2002. En síntesis, el Informe Aldama (2003) trata las mismas cuestiones que el Informe Olivencia, introduciendo algunas nuevas relativas a especificar los deberes de lealtad y diligencia y definir lo que se entiende por conflictos de intereses. El hasta ahora último capítulo de este tema lo constituye el Informe Conthe que el 22 de Mayo de 2006 publicó el Código Unificado de Buen Gobierno ${ }^{34}$, actualización de los precedentes informes Olivencia y Aldama. Este último Código se basa en el principio de voluntariedad con sujeción al artículo 116 de la Ley del Mercado de Valores, que obliga a las sociedades a consignar en su Informe Anual de Gobierno Corporativo, "el grado de seguimiento de las recomendaciones de gobierno corporativo, o en su caso, la explicación de la falta de seguimiento de dichas recomendaciones". Las sociedades que cotizan, con independencia de su tamaño ${ }^{35}$, deben libremente decidir si siguen o no las recomendaciones, pero en todo caso deben explicar el porqué. Serán los accionistas, los inversores y el propio mercado quienes valoren las explicaciones.

33 Ver M. Olivencia Ruíz (1994) "Tendencias actuales en la administración de la sociedad anónima", Revista General de Derecho, núm. 603, diciembre, pp. 12833-12844. Y este mismo autor en 'Managers' revolution/Independents' Counter-revolution (Ensayo sobre una nueva fase de la sociedad anónima)", Estudios Menéndez, Madrid, t. II, pp. 2173-2193.

34 Acuerdo del Gobierno de 29 de Julio de 2005, por el que crea un Grupo Especial de Trabajo para Asesorar a la Comisión Nacional del Mercado de Valores en la Actualización de los Informes Olivencia y Aldama.

35 Aunque el propio Código Unificado reconoce que algunas recomendaciones son muy onerosas para las pequeñas sociedades. 
La Comisión Nacional del Mercado de Valores no podrá sancionar a aquellas sociedades que no hayan seguido las recomendaciones. Nos seguimos moviendo en el ámbito voluntario de la ética. Sin embargo, esta materia de buen gobierno corporativo conlleva dos matices importantes que la diferencian de la ética en los negocios en general y la responsabilidad social empresarial en particular, con las que comparte evidentes identidades. En primer lugar, algunas de las recomendaciones sobre buen gobierno no se encuentran dentro de la ética, sino que son más bien un intento de racionalizar el funcionamiento de las sociedades mercantiles. Nos referimos a cuestiones sobre la dimensión de los consejos, su composición, duración del mandato, su funcionamiento, etc. Es decir, una sociedad no actúa de manera más o menos ética por el hecho de que el número de consejeros sea mayor o menor, haya más o menos consejeros externos o su mandato sea de más o menos duración. 0 , al menos, no son cuestiones estrictamente éticas, como sí lo sería, la responsabilidad o la retribución de los miembros del consejo. En segundo lugar, los códigos de buen gobierno han dado lugar a la promulgación de normas de derecho positivo, así la Ley 26/2003, de 17 de Julio, que modificó la Ley de Sociedades Anónimas y la Ley del Mercado de Valores, con el fin de reforzar la transparencia de las sociedades anónimas cotizadas; y la Orden del Ministerio de Economía 3722/2003, de 26 de Diciembre, sobre el informe anual de gobierno corporativo y otros instrumentos de información de las sociedades anónimas cotizadas y otras entidades.

\section{A MODO DE RESUMEN Y CONCLUSIÓN}

Es evidente, al menos en el plano teórico, que hoy en día existe una preocupación cada vez mayor por el comportamiento ético de las organizaciones empresariales, tendencia que se ha hecho extensible también a actividades no comerciales, como por ejemplo, la de los responsables políticos y altos cargos de la administración pública ${ }^{36}$.

El tema de la ética en el mercado plantea, cuando menos, dos grandes cuestiones aún no totalmente resueltas. En primer lugar, qué se entiende por comportamiento ético, ya que al tratarse de un concepto muy amplio es necesario determinar qué comportamientos concretos son

36 El Consejo de Ministros de 18 de febrero de 2005 aprobó el Código de Buen Gobierno de los miembros del Gobierno y de los altos cargos de la Administración General del Estado. 
éticos y cuáles no lo son. $\mathrm{Y}$, en segundo lugar, partiendo de la base de que hablamos de actividades voluntarias, y al no encontrarnos en el ámbito del derecho positivo, cómo convencer a las empresas para qué actúen éticamente.

A la primera cuestión, el contenido de la ética empresarial, se ha respondido tan sólo en parte circunscribiéndola a un concepto mucho menos amplio como es el de responsabilidad social corporativa o empresarial, como actitud que engloba comportamientos enfocados fundamentalmente hacia los trabajadores, la sociedad (comunidad) y el medio ambiente. Existen iniciativas y documentos suficientes para asegurar su comprensión. Sin contar con las numerosas organizaciones, amén de las ya referidas, que contribuyen a su fomento e implantación ${ }^{37}$. No obstante, a pesar de reconocer los grandes avances en esta materia, el que una empresa sea socialmente responsable, si bien implica que su comportamiento en parte es ético, no significa que lo sea en su totalidad. La proliferación de códigos éticos o códigos de conducta, estableciendo públicamente los valores de referencia que deben regir el comportamiento de los miembros de una organización o los que intervienen en un sector determinado de la actividad económica, son también una manera de concretar el contenido de la ética en el mercado. Estos códigos pueden basarse en los principios de la responsabilidad social corporativa o no y siempre son positivos, en cuanto implican el sometimiento a normas públicas de conducta, pero tampoco garantizan, por la lógica generalidad de sus disposiciones y la dificultad de su aplicación e interpretación, que su fiel seguimiento implique una conducta ética intachable.

Respecto a la segunda cuestión, la forma de conseguir el convencimiento de quienes deben actuar éticamente, creemos que no deberían bastar los argumentos económicos. Éstos, sin duda importantes, no ayudan a crear bases sólidas sobre las que debe asentarse la ética empresarial. Cuando se defiende la ética como estrategia empresarial adecuada, en cuanto genera confianza y permite asegurar la viabilidad de la empresa, no siempre se tiene en cuenta que ésta es una cuestión que se ha de conseguir a largo plazo y que no es fácilmente mensurable ni tan siquiera, en muchos casos, demostrable. Renunciar a un mayor beneficio

37 Aceras, Fundación Empresa y Sociedad, Fundación Codespa, Fundación Entorno, Observatorio de la Responsabilidad Social Corporativa, Red Puentes, Responsable biz, World Business Council for Sustainable Development, etc. 
a corto o medio plazo, a cambio de obtener la confianza necesaria para que a largo plazo tal beneficio sea mayor, no es un axioma que todas las empresas estén dispuestas a seguir. Se ha hecho un excesivo esfuerzo de abstracción en tanto que siempre se habla de la empresa, la cultura empresarial, el liderazgo, cuando el comportamiento ético al fin y al cabo sólo se puede predicar de los seres humanos. Las decisiones no las toma la empresa, sino sus directivos. Hay que concienciar a éstos de la necesidad de un comportamiento ético por la simple verdad de que la bondad y la justicia deben ser argumentos tan universales como para que no sea necesario acudir a ningún otro. A partir de aquí ya se podrán construir todo tipo de útiles y teorías. Pero partamos de la idea irrefutable y universalmente aceptada de que quien actúa éticamente lo hace por convencimiento de lo que debe ser.

\section{BIBLIOGRAFÍA}

CONILL, J. y D. GARCíA-MARZÁ (2004) "Responsabilidad social corporativa: ¿ética, derecho o filantropía?, XV Seminario Permanente de Ética Económica y Empresarial (2004-2005). Ética de la Empresa: "Hacia un Nuevo Orden Global", Valencia, Fundación Étnor, pp. 118-125.

CORTINA ORTS, A. (Coord.) (2003) Construir confianza: ética de la empresa en la sociedad de la información y las comunicaciones. Madrid: Trotta.

- (2005) "Hacia una nueva cultura empresarial (1994-2005)", XV Seminario Permanente de Ética Económica y Empresarial (2004-2005). Ética de la Empresa: "Hacia un Nuevo Orden Global", Valencia, Fundación Étnor, pp. 7-19.

DAVIS, K. (1990) "Five Propositions for Social Responsibility", HofFMAN, W.M.; MILLS, J.; MOORE, J.: Business Ethics: Readings and Cases in Corporate Morality. New York: McGraw-Hill.

DURÁN-PICH, A. (2005) "¿Es la ética en los negocios un oxímoron?. Una aproximación contextual a un tema controvertido", XIV Seminario Permanente de Ética Económica y Empresarial (2004-2005). Ética de la Empresa: "Hacia un Nuevo Orden Global". Valencia, Fundación Étnor, pp. 31-45.

FERNÁNDEZ DE LA GÁNDARA, L. (1993) "Derecho. Ética y Negocios", Discurso de Apertura del curso 1993/94 en la Universidad de Alicante, Alicante. 
FrIedMAN, M. (1982) Capitalism and Freedom. Chicago: University of Chicago Press.

GALBRAITH, J.K. (1958) The Affluent Society. New York: Mariner Books.

IÑIGo FUSTER, A. (2003) "Nulidad y usura. La nulidad del préstamo usurario a la luz de la Ley de Represión de la Usura", Sentencias de Tribunal Supremo, Audiencias Provinciales y otros tribunales, núm. 16, Pamplona: Aranzadi.

LARENZ, K. (1993) Derecho justo: fundamentos de ética jurídica. Madrid: Civitas.

Le Tourneau, P. (2000) La Ética de los Negocios y de la Administración en el Siglo XXI. Burdeos.

OlivenCia Ruíz, M. (1994) "Tendencias actuales en la administración de la sociedad anónima", Revista General de Derecho, núm. 603, diciembre, pp. 12833-12844.

- (1996) "Managers' Revolution/Independents' Counter-revolution (Ensayo sobre una nueva fase de la sociedad anónima)", Estudios Menéndez, Madrid, t. II, pp. 2173-2193.

ORozco Pardo, G. (2002) "Protección de los consumidores, condiciones generales y cláusulas abusivas. Varias reflexiones y un ejemplo: el sistema francés de amortización de créditos hipotecarios", Aranzadi Civil, núm. 10, pp. 15-58. 